\section{Memória em movimento: \\ a participação brasileira na comunidade mundial das ciências da comunicação'}

\section{RESUMO}

Tomando como cenário a conjuntura da Guerra Fria, 0 autor reconstitui a fundação da comunidade mundial das ciências da comunicação, focalizando a institucionalização da IAMCR , para, em seguida, destacar a participação brasileira nesse mutirão acadêmico. Privilegia o papel desempenhado pela INTERCOM em tal processo histórico, fazendo um balanço crítico das suas tendências e perspectivas.

\section{ABSTRACT}

Choosing the scenario of the Cold War as his take-off point, the author rescues the foundation of the world community of communication sciences, focusing on the institution-alization of IAMCR, and then the Brazilian participation in this academic journey. He gives special attention to the role played by INTERCOM in this historic process, at the same time he does a critical review of its tendencies and perspectives.

\section{PALAVRAS-CHAVE (KEY WORDS)}

- História da comunicação (History of communication)

- Ciências da comunicação (Communication Sciences)

- IAMCR e INTERCOM (IAMCR and INTERCOM)

José Marques de Melo² UMESP

\section{A conjunfura do pós-guerra}

A RECONSTITUIÇÃO DA COMUNIDADE internacional, durante o pós-guerra, e a construção de um novo cenário mundial - a guerra fria.- demandam conhecimentos sobre os processos comunicacionais, tendo em vista o papel crucial desempenhado pela mídia, quer no tocante à hegemonia informativa, quer no referente ao potencial educativo das novas tecnologias de difusão cultural.

A UNESCO, com sede em Paris, converte-se em fórum legitimado para a formulação de políticas comunicacionais capazes de balizar os conflitos entre povos e nações, assumindo uma postura no sentido de fortalecer a paz mundial e de criar mecanismos destinados a reduzir as carências cognitivas dos países sub-desenvolvidos. Emerge, nessa ocasião, o conceito de terceiro mundo, em certo sentido transformado em objeto de disputa ideológica entre os blocos "capitalista" e "socialista". Nesse embate, o "bloco socialista" mostra-se inicialmente favorecido, sobretudo depois da vitória dos comunistas chineses, liderados por Mão Tse Tung (1949).

Torna-se imprescindível aos líderes mundiais o monitoramento do fluxo mundial de notícias, bem como a implementação de mecanismos destinados a "queimar etapas" na socialização do conhecimento. Isso justifica a contratação de cientistas do porte de Jacques Kayser (França) e Wilbur 
Schramm (Estados Unidos) para assessorar o seu staff na "tomada de decisões estratégicas".

Nesse contexto, a UNESCO empenhase em criar condições para o fortalecimento das comunidades acadêmicas no âmbito das "ciências sociais", organizando inventários bibliográficos e estimulando reuniões internacionais destinadas a produzir repertórios cognitivos (state of art) em diferentes disciplinas.

Em meados dos anos 50, intensifica-se a demanda por conhecimentos comunicacionais, na sua vertente midiática. Ela é correspondida, inicialmente, através de levantamentos documentais que possam subsidiar os debates dos delegados nacionais nas assembléias gerais da instituição. Um produto dessa ofensiva é o inventário Recherches actuelles sur les moyens de l'information (1957). Contudo, tal opção mostra-se insuficiente, pois os formuladores de políticas internacionais nos campos da educação, ciência e cultura necessitam de conhecimentos novos, atualizados, provindos de estudos de campo. Informações dessa natureza estavam disponíveis, coletadas tanto por empresas privadas (public opinion and audience studies) quanto pelos departamentos de pesquisa das empresas estatais de RTV. Sua natureza era, contudo, espacial e temporalmente limitada, havendo carência de estudos holísticos, prospectivos e comparativos.

Nada mais adequado para lograr esse objetivo do que organizar a comunidade dos pesquisadores dos meios de comunicação, da mesma forma que já vinha ocorrendo com os sociológicos, antropólogos ou cientistas políticos.

\section{Formação de uma comunidade}

A mobilização dessa comunidade teve como marco fundador a realização da Conferência Constitutiva da Associação Internacional de Estudos e Pesquisas sobre a Informação (essa expressão francesa foi traduzida em inglês para Mass Communication nos dias 18-19 de dezembro de 1957.
Dois países estiveram na vanguarda dessa iniciativa: a França, liderada por Fernand Terrou e Jacques Kayser, dirigentes do Instituto Francês de Imprensa, e Estados Unidos da América, representados por Raymond Nixon, dirigente da Association for Education in Journalism, editor da renomada revista Journalism Quartely. Sustentaram esse movimento os seguintes países: Itália, representada por Francesco Fatorello e Domenico de Gregório, Suíça, representada por Jacques Bourquin, Polônia, representada por Mieszyslaw Kafel , e Tchecoslováquia, representada por Jiri Pilar e Vlamidir Klimes.

A primeira diretoria da entidade foi eleita em Paris, 1957, mas a estrutura consolidada da associação só foi definida na assembléia de 6 de outubro de 1959, em Milão, Itália.

O quadro social dessa associação representativa da comunidade internacional dos pesquisadores da comunicação de massa era integrada por: acadêmicos (vinculados a instituições universitárias), profissionais (representantes de organizações sindicais ou de empresas midiáticas) e funcionários (representantes governamentais ou técnicos vinculados a agências internacionais).

\section{Presença brasileira}

O Brasil se fez representar na fundação da AIERI por Danton Jobim, cuja cooptação se fez por intermédio de Jacques Kayser, que o havia convidado para ministrar curso na Sorbonne, no início de 1957, publicado sob a forma de livro com o título Introduction au Journalisme Contemporaine.

A participação de Danton Jobim contou evidentemente com o beneplácito de Raymond Nixon, responsável pela publicação, em 1954, do seu artigo French and US. influences upon the Latin American press, na revista Journalism Quartely (seção Foreing Communication, editada por Robert Desmond, também assessor da UNESCO).

Jobim apresentava um perfil híbrido, que lhe permitia transitar entre a academia 
e o mercado, uma vez que acumulava, na ocasião, a função de editor do jornal Diário Carioca e professor do Curso de Jornalismo da Universidade do Brasil.

O prestígio intelectual que desfrutava entre as lideranças da nova comunidade rendeu-lhe a eleição para ser Vice-Presidente da Conferência fundadora da AIERI, bem como sua escolha para integrar o Comitê Executivo da nova associação, em Paris, posição que foi confirmada em 1959, em Milão, durante a constituição da sua primeira diretoria ordinária.

Trata-se, contudo, de uma participação simbólica, resultante muito mais do reconhecimento das potencialidades brasileiras nessa área, do que do capital intelectual acumulado. Em seu livro Espírito do Jornalismo (1960), Jobim registra as dificuldades com que se defrontavam os acadêmicos do jornalismo em nosso país, embora demonstre confiança no porvir, tanto assim que faz o esboço de um programa de pesquisas para a sua universidade.

A leitura dos documentos constitutivos da AIERI indica o simbolismo da participação brasileira, não havendo menção a intervenções de Jobim nos debates, cujos protagonistas são principalmente os representantes europeus, coadjuvados pelos norte-americanos.

Tal ausência reflete também a indisponibilidade do nosso representante para função dessa natureza, comprometido com suas atividades empresariais na direção de um jornal diário, dispondo de tempo curto para cumprir suas responsabilidades acadêmicas. Tanto assim que não participou das reuniões do comitê executivo da associação, realizadas em cidades européias como Praga, Moscou ou Paris, nem mesmo da assembléia constitutiva de Milão.

Durante a primeira fase da vida da AIERI, Danton Jobim figurou como membro dos seus diretórios, não parecendo ter exercido papel ativo, nem mesmo como mediador para ampliar a participação brasileira naquele fórum internacional. Aliás, seria inadequado cobrar-lhe tal protagonismo, tendo em vista a insipiência das atividades investigativas sobre mídia e jornalismo em nosso país, principalmente nas universidades.

A mudança do cenário só se viria a ocorrer em meados dos anos 60 , como conseqüência do papel exercido pelo CIESPAL, fundado em 1959, em Quito, Equador. Danton Jobim veio a ter participação destacada na criação dessa entidade, representando o Brasil na reunião preparatória de 1958, bem como no ato de sua fundação em 1959. Posteriormente veio a integrar o corpo docente daquele centro internacional, onde assumiu a cátedra de Pedagogia do Jornalismo, cujas aulas foram depois publicadas em livro.

Sucedeu Danton Jobim na interlocução brasileira com a AIERI o professor José Freitas Nobre, que logo depois do golpe militar de 64 refugiou-se em Paris, dedicando-se a estudos doutorais, sob a orientação de Fernand Terrou, fundador e ex-presidente da AIERI.

Foi por intermédio de Freitas Nobre que me filiei à AIERI, justamente no período de implantação da ECA-USP. Outro filiado ocasional foi o primeiro diretor da ECA, Julio Garcia Morejón, guindado ao diretório da entidade por intermédio de Juan Beneyto, então presidente do Conselho Nacional de Imprensa e presidente do Comitê Nacional da AIERI na Espanha.

Durante os anos 70, dois brasileiros tiveram presença marcante na AIERI - Fernando Perrone, exilado brasileiro em Paris, e Nelly de Camargo, docente da ECA-USP.

Foi por intermédio de Perrone que se cogitou uma maior integração da comunidade brasileira com a comunidade internacional de ciências da comunicação. Ele chegou a propor o Brasil como sede de uma conferência bienal da associação, não logrando convencer as suas lideranças, certamente ressabiadas pela presença residual de brasileiras em suas reuniões periódicas, inclusive nas duas que se realizaram na América Latina - Argentina (1970) e Caracas (1980).

Essa integração veio a ser construída a partir da consolidação da INTERCOM, que 
assumiu a ofensiva para sediar em território nacional uma conferência mundial de ciências da comunicação. Esse projeto foi implementado em 1992 (Guarujá) e voltará a ser replicado em 2004 (Porto Alegre).

\section{Papel da Infercom}

Desde a sua fundação a INTERCOM vem atribuindo função decisiva à cooperação internacional, justamente para garantir legitimidade intelectual ao conhecimento produzido por seus associados. Essa tese foi largamente disseminada no Boletim Intercom, que noticiou eventos, disseminou pesquisas e divulgou publicações de outros países. Quando assumiu o formato de $R e-$ vista Brasileira de Ciências da Comunicação, tal missão foi ampliada e reforçada, através da veiculação de ensaios ou artigos escritos por eminentes pesquisadores legitimados pela comunidade internacional.

Da mesma forma, a entidade estimulou a interlocução com lideranças emblemáticas do nosso campo. Alguns daqueles autores estrangeiros mais lidos e acatados na academia brasileira tiveram seus primeiros contatos com a nossa comunidade através da INTERCOM. Exemplos principais: os europeus Armand Mattelart, Adriano Duarte Rodrigues, Enrique Bustamente, Bernard Miége, os norte-americanos Everett Rogers, Emile McAnany, Joseph Straubahaar, os latino-americanos Rafael Roncagliolo, Jesus Martin Barbero, Nestor Garcia Canclini, Juan Gargurevich, Javier Esteinou Madrid, o australiano John Sinclair etc.

Contudo, a ofensiva para a internacionalização da nossa comunidade acadêmica teve como marco o Congresso mundial da AIERI, em Barcelona. Ali foram esboçadas três frentes de atuação que renderam dividendos à participação brasileira na comunidade mundial das ciências da comunicação: 1 - A filiação brasileira, enquanto coletivo de cientistas, que marcou nossa presença na conferência de Bled (1990) e justificou a escolha do Brasil para sediar a conferência de (Guarujá), reforçando nossa participação destacada nas conferências de Seul (1994), Sidney (1996) e Glasgow (1998). Depois do declínio de Singapura (2000), voltamos a intensificar nossa participação em Barcelona (2002). Agora, temos oportunidade de demonstrar os nossos avanços, neste evento que precede a conferência de Porto Alegre (2004).

2 - A liderança assumida pelo Brasil na reconstituição da ALAIC e conseqüentemente no fortalecimento da comunidade latinoamericana de ciências da comunicação. Sediamos dois congressos da ALAIC em território nacional: Embu-Guaçu (1992) e Recife (1998). Coube a dois brasileiros presidir a entidade: José Marques de Melo (19891992) e Margarida Kunsch (2000-2004).

3 - O desenvolvimento de uma linha de trabalho que se vem realizando promissora: a organização de colóquios bi-nacionais, na tentativa de criar relações orgânicas com associações congêneres de outros países. Em Barcelona foi esboçada a primeira conexão: INTERCOM / SFISC, cujo primeiro fruto foi o Colóquio Brasil-França de Ciências da Comunicação (São Paulo, 1992).Desde então, iniciativas semelhantes foram sendo engendradas com núcleos investigativos da Espanha, Dinamarca, Inglaterra, Itália, México, Canadá e recentemente Estados Unidos.

\section{Balanç○ necessário}

O que logramos contabilizar positivamente nesse processo de articulação com a comunidade mundial da nossa área de conhecimento ?

Conquistamos evidência mundial, especialmente pelo tamanho do nosso mercado como consumidor potencial das idéias germinadas no exterior. Corremos, por isso mesmo, o perigo de nos transformar em simples mercado de reserva para autores que necessitam de legitimação extra-muros, mas cujas criações intelectuais muitas vezes configuram "idéias fora do lugar" (para não 
dizer "fora do tempo").

Em contrapartida, não adquirimos o hábito de acompanhar organicamente as tendências legitimadas pela comunidade mundial. Basta uma verificação acurada nas teses de mestrado e doutorado defendidas em nossas universidades para verificar como estamos distantes das correntes de pensamento internacionalmente reconhecidas.

Se isso não bastasse, deixamos em segundo plano a difusão das idéias originais que temos produzido, tanto pela nossa presença bissexta nos periódicos internacionais da área quanto pela timidez com que temos disseminado, em língua inglesa ou espanhola, o pensamento comunicacional brasileiro. A antologia organizada por Antonio Hohlfeldt e Maria Cristina Gobbi, aqui difundida, significa o resgate da iniciativa que a ECA-USP tomou no biênio 1992-1993 ao lançar a Brazilian Communication Research Yearbook. Ela se complementará com o projeto da nova revista internacional Brazilian Journalism Research anunciada pela recémfundada Sociedade Brasileira de Pesquisa em Jornalismo (SBPJor).

Vale a pena refletir sobre essa questão no momento em que recepcionamos, mais uma vez, a vanguarda da nossa comunidade internacional e pouco tempo depois de nos reunirmos com os representantes da principal comunidade nacional, a norteamericana.

A cooperação internacional é indispensável num mundo que se globaliza aceleradamente, mas ela só vale a pena ser fortalecida se trouxer dividendos para todos os parceiros em conexão •

\section{Notas}

1 Comunicação apresentada ao Seminário "O Pensamento Comunicacional Brasileiro", realizado na cidade de Porto Alegre, no dia 25 de julho de 2004, como atividade integrante da XXIV Conferência Internacional da Inter-national Association for Media and Communication Research (IAMCR).
2 Professor Emérito da Escola de Comunicações e Artes da Universidade de São Paulo e Presidente de Honra da Sociedade Brasileira de Estudos Interdisciplinares da Comunicação. Foi Vice-Presidente da International Association for Media and Communication Research (período 1992-1996). Atualmente é Professor do Programa de Pós-Graduação em Comunicação Social da Universidade Metodista de São Paulo, onde dirige a Cátedra UNESCO de Comunicação para o Desenvolvimento Regional.

\section{Referências}

BOURQUIN, Jacques. Assocation Internationale des Études et Recherhes sur l Information: Documents Historiques, 1957-1967, Praga, International Journalisme Institute, 1989.

JOBIM, Danon. Espírito do Jornalismo, Rio de Janeiro, São José, 1969 (2a. edição, São Paulo, EDUSP, 1992.

HOLFELDT, Antonio \& GOBBI, Maria Cristina (orgs.). Teoria da Comunicação: Antologia de Pensadores Brasileiros, Porto Alegre, Edipurs, 2004.

MARQUES DE MELO, José. Teoria da Comunicação: paradigmas latino-americanos, Petrópolis, Vozes, 1998.

MARQUES DE MELO, José. História do Pensamento Comu-nicacional, São Paulo, Paulus, 2003.

MARQUES DE MELO, José. A esfinge midiática, São Paulo, Paulus, 2004.

PERUZZO, Cicília e MOREIRA, Sonia. Intercom, 25 anos, São Paulo, Intercom, 2004. 